BNL-72491-2004-CP

\title{
Numerical Simulation on Thermal Stress and Magnetic Forces of Current Leads in BEPC II
}

\author{
L. X. Jia et al \\ Presented at the $20^{\text {th }}$ International Cryogenic Engineering \\ Conference \& Exhibition \\ Beijing, China \\ May 11-14, 2004
}

July 2004

\author{
Collider-Accelerator Department \\ Brookhaven National Laboratory \\ P.O. Box 5000 \\ Upton, NY 11973-5000 \\ www.bnl.gov \\ Managed by \\ Brookhaven Science Associates, LLC \\ for the United States Department of Energy under \\ Contract No. DE-AC02-98CH10886
}

This is a preprint of a paper intended for publication in a journal or proceedings. Since changes may be made before publication, this preprint is made available with the understanding that it will not be cited or reproduced without the permission of the author. 


\title{
DISCLAIMER
}

This report was prepared as an account of work sponsored by an agency of the United States Government. Neither the United States Government nor any agency thereof, nor any of their employees, nor any of their contractors, subcontractors, or their employees, makes any warranty, express or implied, or assumes any legal liability or responsibility for the accuracy, completeness, or any third party's use or the results of such use of any information, apparatus, product, or process disclosed, or represents that its use would not infringe privately owned rights. Reference herein to any specific commercial product, process, or service by trade name, trademark, manufacturer, or otherwise, does not necessarily constitute or imply its endorsement, recommendation, or favoring by the United States Government or any agency thereof or its contractors or subcontractors. The views and opinions of authors expressed herein do not necessarily state or reflect those of the United States Government or any agency thereof.

\section{FOR UNCLASSIFIED, UNLIMITED STI PRODUCTS}

Available electronically at:

\section{OSTI:}

http://www.osti.gov/bridge

Available for a processing fee to U.S. Department of Energy and its contractors, in paper from:

\author{
U.S. Department of Energy \\ Office of Scientific and Technical Information \\ P.O. Box 62 \\ Oak Ridge, TN 37831 \\ Phone: (865) 576-8401 \\ Facsimile: (865) 576-5728 \\ E-mail: reports@adonis.osti.gov
}

\section{National Technical Information Service (NTIS):}

Available for sale to the public from:

U.S. Department of Commerce

National Technical Information Service

5285 Port Royal Road

Springfield, VA 22131

Phone: (800) 553-6847

Facsimile: (703) 605-6900

Online ordering: http://www.ntis.gov/ordering.htm 


\title{
Numerical Simulation on Thermal Stress and Magnetic Forces of Current Leads in BEPC II *
}

\author{
Zhang X.B. ${ }^{1}$ and Jia L.X. ${ }^{2}$ \\ ${ }^{1}$ Institute of Cryogenics and Superconductivity Technology, Harbin Institute of Technology, Harbin 150001, CHINA \\ ${ }^{2}$ Brookhaven National Laboratory, Upton, New York 11973, USA
}

\begin{abstract}
Six pairs of low current leads are used for the superconducting interaction quadruple magnets (SCQ) in the Beijing Electron Positron Collider Upgrade (BEPCII). This paper presents analyses on the magnetic field induced by the current lead bundle as well as the magnetic forces on the leads. The thermal stress of the single lead is investigated. The stress of interference fitting for a novel insulator used for the current leads at various operating temperatures is analyzed.
\end{abstract}

\section{INTRODUCTION}

One pair of current leads with nominal current $1600 \mathrm{~A}$, two pairs with nominal current $630 \mathrm{~A}$ and three pairs with nominal current $150 \mathrm{~A}$ have been designed for the SCQ magnet in BEPCII. Figure 1 shows the schematic diagram of the current lead bundle. A novel cryogenic electrical isolator has also been designed for the leads. With the FEM software package ANSYS, this paper presents numerical simulation on the magnetic field of the current lead bundle induced by the operating current. The thermal stress of the $1600 \mathrm{~A}$ current lead is investigated in detail. The stress of interference fitting for the insulator at various operating temperatures is analyzed to avoid the failure of the involved material.

\section{MAGNETIC FIELD OF CURRENT LEAD BUNDLE}

The numerical model of the current lead bundle for the magnetic field simulation is shown in Figure 2. The relative location of the current leads carrying different current flux is indicated. The symbols " + " and "." indicate the current direction. The equivalent inner diameter $d_{e}$ is introduced to simplify the

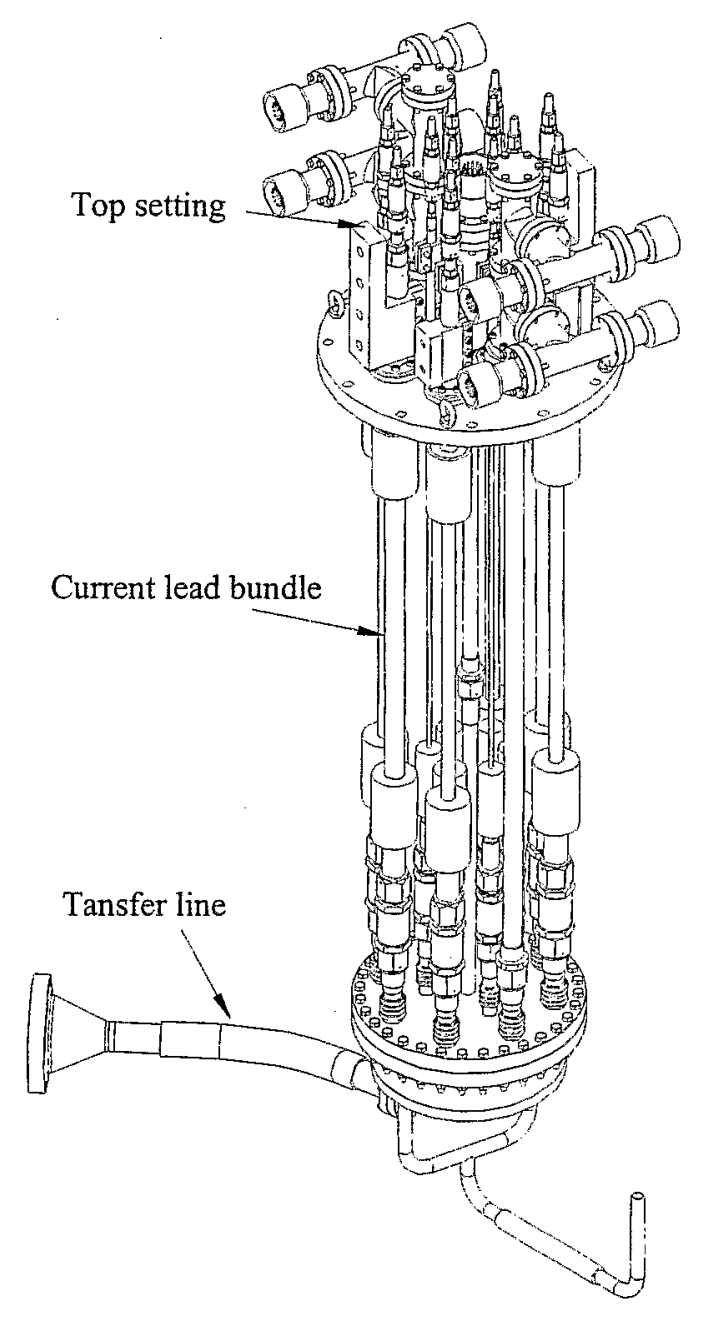

Figure 1 Current lead bundle for the SCQ magnet in BEPC II. 
multi-pipe structure [1] of the current leads based on the same cross section area. Both the copper and vacuum have the same relative magnetic permeability of 1 , and no external magnetic field is applied. The vacuum shield and other transfer tubes are neglected for their little effects on the magnetic field. The far field is used to explain the infinite field beyond the interesting zone of the current lead bundle. Figure 3 shows the magnetic intensity and the isochronous magnetic force applied to the left

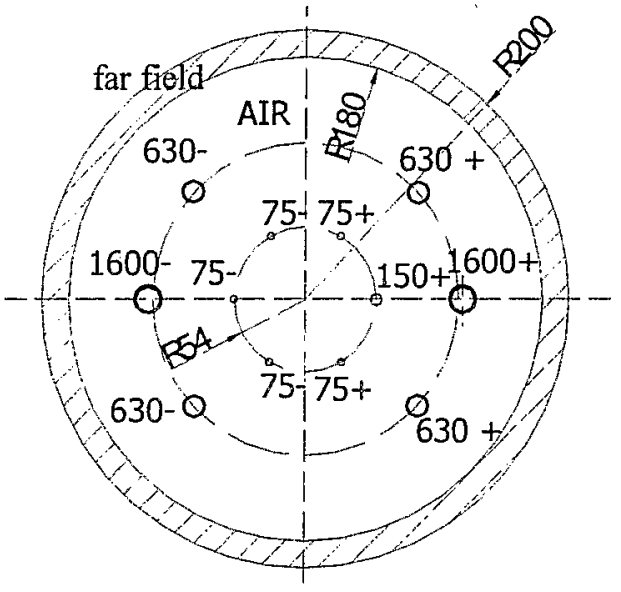

Figure 2 Model of magnetic field simulation of the current lead bundle.

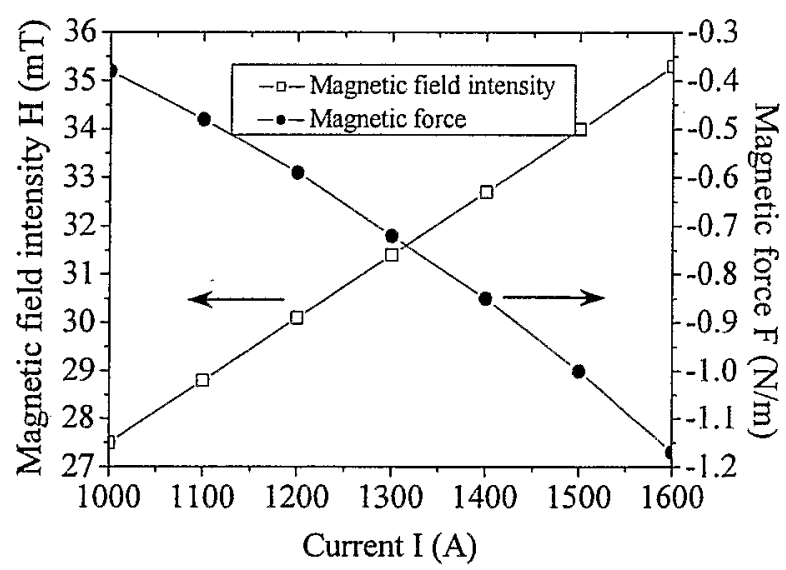

Figure 3 Variation of magnetic force $F$ and magnetic field Intensity $H$ as function of maximum current $I$.

$1600 \mathrm{~A}$ current lead at different current $I$. The maximum magnetic flux density of $0.035 \mathrm{~T}$ is found in the vicinity of the $1600 \mathrm{~A}$ current leads for the normal operation. This value reveals that the effect on the accuracy of the silicon diode thermometers is inappreciable [2]. The symbol minus for the magnetic force means that the lead is pushed back from the right $1600 \mathrm{~A}$ lead. When $I=1600 \mathrm{~A}$, the maximum magnetic force $-1.17 \mathrm{~N} / \mathrm{m}$ is applied to the $1600 \mathrm{~A}$ current leads. This corresponds to the stress of $52.7 \mathrm{pa}$ with its outer diameter of $22.22 \mathrm{~mm}$. Obviously, the magnetic intensity and the magnetic force keep consistent change with the excited current (see Figure 3).

\section{THERMAL STRESS OF 1600A CURRENT LEAD}

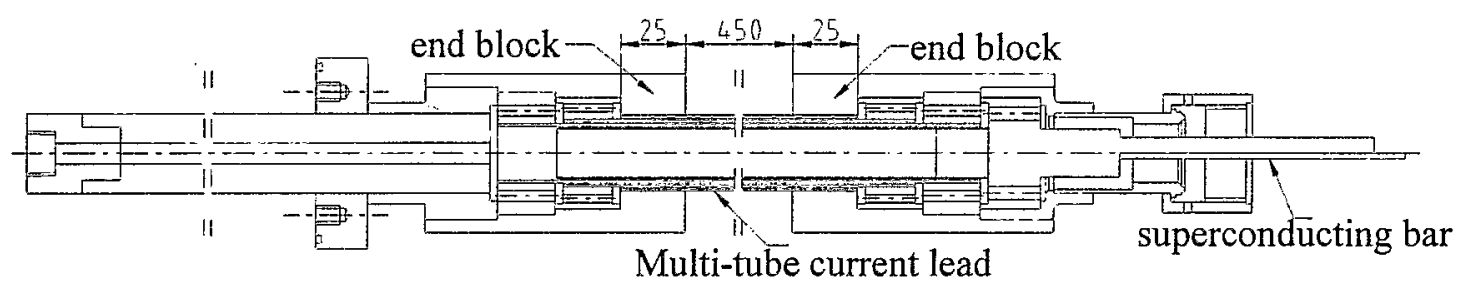

Figure 4 Schematic diagram of the 1600A current lead for the SCQ magnet

The thermal stress of the leads cooled down from room temperature to the operating temperature has great effluence on the lead performance. The temperature distribution along the gas-cooled current lead by the numerical analysis on thermal process has been studied [3]. For the multi-tube current lead of $1600 \mathrm{~A}$ (see Figure 4), axisymmetric condition is adopted for simplifying the simulation model. Considering their similar temperature distribution and connecting fashion, only outer tube of the multiple tubes is modeled. The length of the lead is $0.45 \mathrm{~m}$ excluding the $25 \mathrm{~mm}$ soldering length with the end copper block (see Figure 4). The tube has the outer diameter of $22.22 \mathrm{~mm}$ with the wall thickness of 
$1.5 \mathrm{~mm}$. The temperature of the hot end block is set at $300 \mathrm{~K}$ and is considered stable along the soldering length for all degrees of freedom. A ripple tube is added below the cold end block to allow thermally shrinking and for convenient assembling of the leads, thus no constraint of degree of freedom is set at cold end block. The Young's modulus and coefficient of thermal expansion of copper are the function of temperature and the Poison ratio of copper is set to 0.3 here [4]. Figure 5 shows the Von Mises stress profile along the outer wall of the tube. It reveals clearly that the stress has almost no effect on the majority of the length of the lead. However, the stress goes up to about 10MPa just at the beginning of the soldering surface at hot end. Fortunately, this value of thermal stress is very

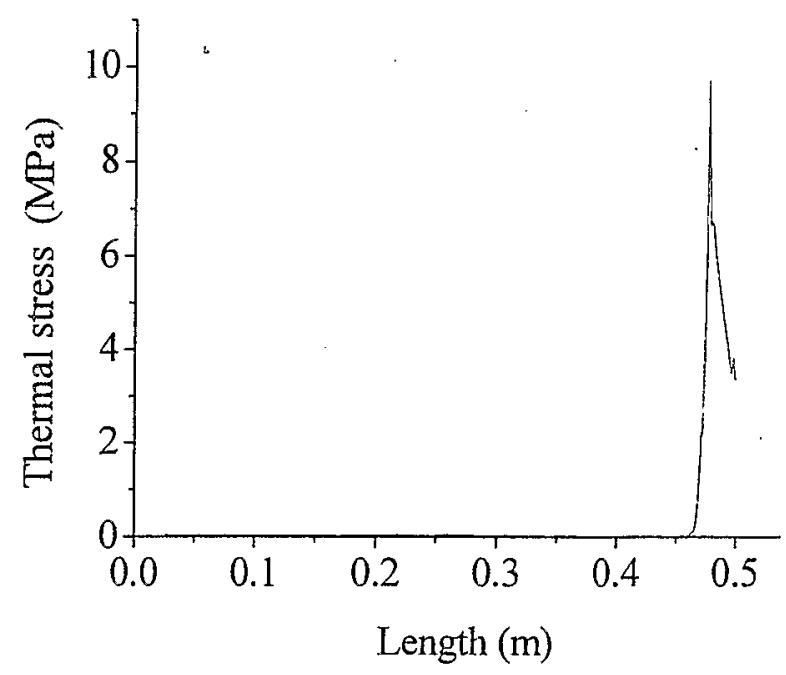

Figure 5 Von Mises stress profile of outer wall along the $1600 \mathrm{~A}$ current lead for the SCQ magnet.

small comparing with the soldering strength we usually acquired.

\section{TRESS OF INSULATOR}

The leads must be electrically insulated at both ends while the cooling gas can go through them. One type of insulator has been designed to meet this requirement. The insulator is consisted of two coaxial tubes. The inner tube is made of $\mathrm{g}-10$ with its outer diameter greater than the inner diameter of the outer aluminum casing at room temperature. The function of aluminum casing is to strengthen the insulator. The helium transfer pipes are connected to the inner tube through the fittings. A quarter of model is appropriate to simulate the contact because of the symmetry of the insulator. Axis-direction displacement of one end of the inner tube is set at zero and no other constraint of degree of freedom is applied.

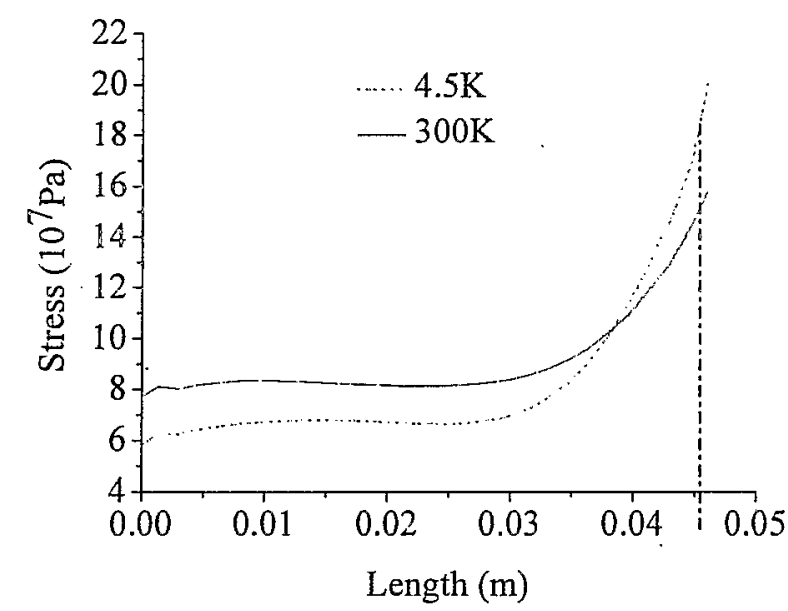

Figure 6 Von Mises stress along the length of the contact surface of the inner tube at $300 \mathrm{~K}$ and $4.5 \mathrm{~K}$.

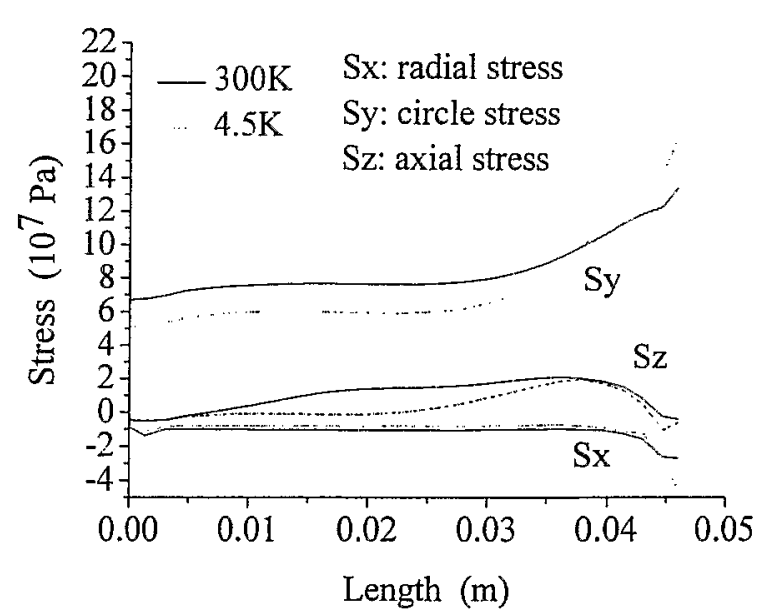

Figure 7 Stress components along the length of the contact surface of the inner tube at $300 \mathrm{~K}$ and $4.5 \mathrm{~K}$.

During simulation two different load steps are defined: The objective of the first load step is to observe the interference fitting stress of the insulator at room temperature. The second load step is to observe the contact stress when the insulator is cooled down to $4.5 \mathrm{~K}$. Figure 6 shows the Von Mises stress profile along the length of the contact surface of the inner tube at $300 \mathrm{~K}$ and $4.5 \mathrm{~K}$. The fixed end of the inner tube has the maximum stress value of $0.135 \mathrm{GPa}$ and $0.2 \mathrm{Gpa}$ at $300 \mathrm{~K}$ and $4.5 \mathrm{~K}$, respectively. A 
strange phenomenon is found that the stress of the contact surface at $300 \mathrm{~K}$ is larger than that at $4.5 \mathrm{~K}$ when the length is less than about $40 \mathrm{~mm}$, but reversed at the rest part. The reason is that aluminum shrinks theoretically more than g- 10 when they are simultaneously cooled down to $4.5 \mathrm{~K}$ and the two will contact more tightly than that at $300 \mathrm{~K}$, while the Young's module of $\mathrm{g}-10$ is decreased from $73.5 \mathrm{GPa}$ at $300 \mathrm{~K}$ to $68.6 \mathrm{GPa}$ at $4.5 \mathrm{~K}[4]$. Besides the radial displacement, there also exits the axial frictional stress and the circle stress (see Figure 7). The circle stress component holds dominant position among these stress components. The constraint on the zero axial displacement at the right end of the inner tube also resists the radial displacements during cooling process, so the circle stress component increases greatly as it approaching to the fixed end, which offsets the reducing of the Young's module of g-10 and finally exceeds the stress at $300 \mathrm{~K}$.

\section{CONCLUSION}

The numerical simulation for the magnetic field induced by the current lead bundle of the SCQ magnet in BEPCII shows that the effect of the magnetic field intensity on the accuracy of silicon diode thermometers is inappreciable, and the magnetic force on each of current leads is negligible by comparing with the thermal stress. When the $1600 \mathrm{~A}$ current lead is cooled down from room temperature to the normal operating temperature, the maximum stress of $10 \mathrm{MPa}$ is found at the soldering place of the warm end from the results of thermal stress simulation. For copper, this stress value is acceptable. The results of the numerical simulation for the novel cryogenic electrical insulator reveal that the maximum stress of the inner tube is $0.135 \mathrm{GPa}$ and $0.2 \mathrm{GPa}$ at $300 \mathrm{~K}$ and $4.5 \mathrm{~K}$ respectively. However, the maximum stress value may be overestimated for the boundary condition of no axial displacement at one end.

\section{REFERENCE}

1. Jia, L.X., Addessi, L.J. et al, Design Parameters for Gas-cooled Electrical Leads of the g-2 Magnets, Cryogenics (1994) $\underline{34} 631-634$

2. Jia, L.X., and Wang, L., Cryogenic Engineering, Harbin Institute of Technology, 20 (interior material)

3. Zhang, X.B., Wang, L., Jia, L.X., Numerical analyses on transient thermal processes of gas-cooled current leads in BEPC II, to be published in Advances in Cryogenic Engineering (2004), 49

4. Ying X., Handbook of Mechanical design, Mechanical Industrial Press, Beijing, China (1991) 2-47 